UCRL-92020

PREPRINT

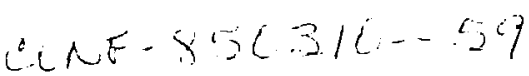

\title{
MODELING AND OPTIMIZATION OF OPERATING YARAMETERS \\ FOR A TEST-CELL OFTIÓN OF THE FUSION POWER DEMONSTRATION-II \\ TANDEM MIRROR DESIGN
}

S. W. Haney and M. E. Fenstermacher

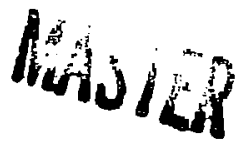

This paper was prepared for submittal to the

6th Topical Meeting on the Technology of Fusion Energy,

San Francisco, California, March 3-7, 1985

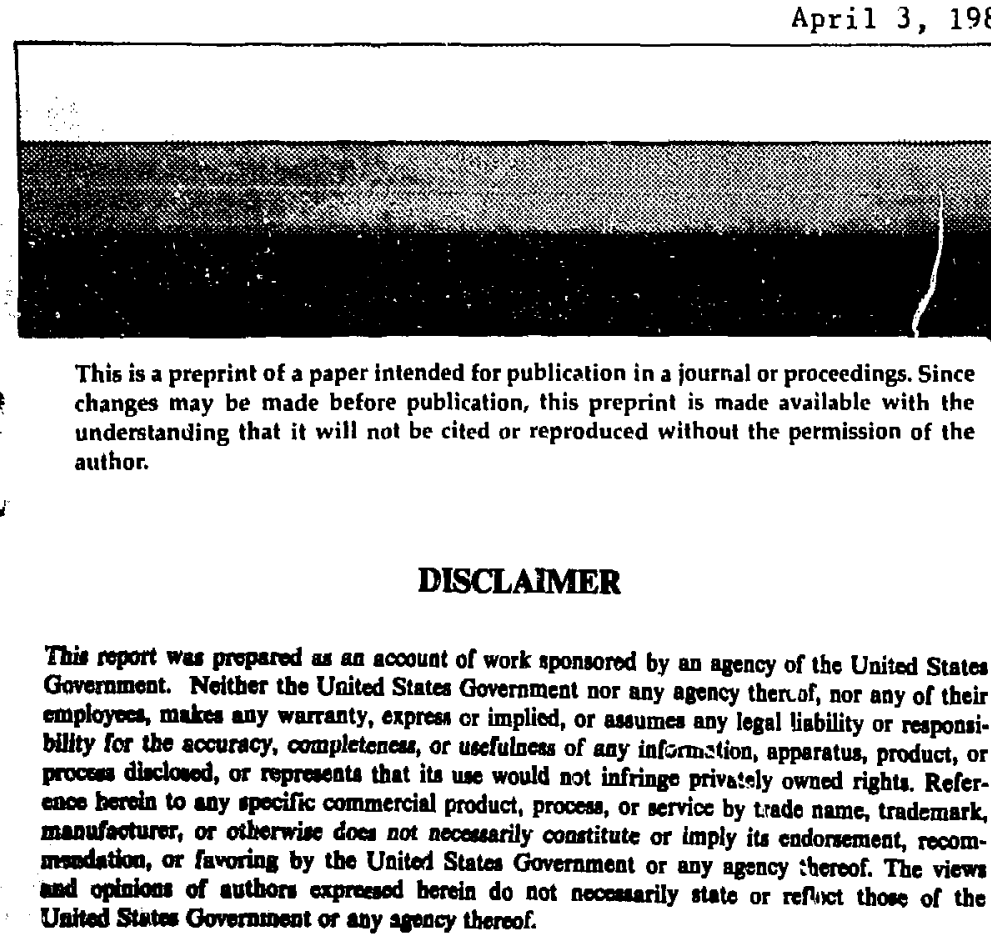

85 
UCRL--92020

DE85 009998

MODELING AND OPT MIIZATION OF OPERATING PARAAETERS FOR A TEST-CELL OPTION OF THE FUSION PONER DEMONSTRATION-II TANDEM MIRROR DESIGN*

S. W. Haney ${ }^{\dagger}$

Massachusetts Institute of Technology

Cambridge, MA 02139

(617) 253-8673
M. E. Fenstermacher ${ }^{+}$

TRW Inc., One Space Park

Redondo Beach, CA 90278

(415) 423-6308

\section{ABSTRACT}

Models of tandem mirror devices operated with a test-cell insert have been used to calculate operating parameters for FPD-II+T, an upgrade of the Fusion Power Demonstration-II device. Two test-cell configurations were considered, one accommodating two $1.5 \mathrm{~m}$ blanket test modules and the other having four. To minimize the cost of the upgrade, FPD-II+T utilizes the same coil arrangement and machine dimensions outside of the test rell as FPD-II, and the requirements on the end cell systems have been held near or below those for FPD-II. The maximum achievable test cell wall loading found for the short test-cell was $3.5 \mathrm{~mW} / \mathrm{m}^{2}$ while $6.0 \mathrm{~mW} / \mathrm{m}^{2}$ was obtainable in the long test-cell configuration. The most severe limitation on the achievable wall loading is the upper limit on test-cell beta set by MHD stability calculations.

Modification of the shape of the magnetic field in the test-cell by improving the magnet design could raise this beta limit and lead to improved test-cell performance.

\section{INTRODUCTION}

The Fusion Power Demonstration, Configuration II (FPD-II), will be a DT burning tandem mirror facility with thermal barriers, designed as the next step engineering test reactor to follow the tandem mirror

\footnotetext{
* Research performed in part in conjunction with the Magnetic Fusion Energy Technology Fellowship program, which is adminigtered for the U.S. Department of Energy by Oak Ridge Associated Universities and by LLNL under contract number W-7405-ENG-48.

tResearch fellow for U.S. Department of Energy Magnetic Fusion Energy Technology Fellowship program at Lawrence Livermore National Laboratory during the summer of 1984.

$+t \star 0 n$ assignment to Lewrence Livermore National Laboratory, P.0. Box 5511, L-644, Livermore, CA 94550.
}

ignition test machines. Current plans call for FPD-II to be a multi-purpose device. For the rirst half of its lifetime, it will operate as a high-Q jgnition machine deaigned to reach or exceed engineering break-even and to demonstrate the technological feasibility of tandem mirror fuaion. The second half of ita operation will focus on the evaluation of candidate reactor blanket designs using a neutral-beam-driven test-cell inaerted at the midplane of the $90 \mathrm{~m}$ long central cell. This machine called EPD-II+T, uses an ingert configuration bimilar to that used in the : $--\alpha+T$ study. 1,2 The modeling and optimization of FPD-II+T are the topica of the present paper.

The test cell used in FPD-II+T has the geometry of a simple, axisymetric mirror. A pair of superconducting coils with normal copper inserts provide peak fields of $15 \mathrm{~T}$ and with additional trim coils produce an average midplane field of $4.7 \mathrm{~T}$. To eliminate cost Iy coil replacement, the magnet configuration outside the test cell remains unchanged from FPD-II. 3 Two test cell mirror-to-mirror lengthe were considerd in this study: $5.1 \mathrm{~m}$ long, accommodating two $1.5 \mathrm{~m}$ wide blanket test modules, and $12.8 \mathrm{~m}$ long, accommodating four blanket test modules. The short test cell will replace a single FPD-II central cell magnet module while the long test cell, with shorter length central cell field coils filling in at the ends, will replace three magnet modules.

The mission of FPD-II+T is to allow relatively inexpensive upgrade of FPD-II to do integrated nuclear material and comporant teating in an environment similar to that predicted for a tandem mirror fusion reactor. This means that test cell designs must be capable of providing neutron wall loadings in the range of 3 to $6 \mathrm{mw} / \mathrm{m}^{2}$ to the blanket test modules. In addition, it would be desirable to provide aufficient tluence to allow blanket test ing to end-of-life. However, 1 imited machine availability makes this unlikely, although enough fluence might be available to surpass the void swelling incubation period in stainleas steels. 
The primary advantage of the FPD-II+T concept over other alternatives also capable of performing integrated nuclear testing is that, as an upgrade of an exiating facility, this capability could perhaps be achieved at lower cost. In particular, significant cost savings could be realized if existing FPD-II reactor aystema could be adapted for use in FPD-I I+T . For thia reason, operating parameters that impact crucial reactor systems (such as drift pumps, ECRH systems, etc.) have been kept to values near, or below, those set for the FPD II baseline machine. The remainder of this paper deals with the design ramifications of these requirements.

The results to be presented in this paper were generated using a version of the TMRBAR 4 tandem mirror reactor physics code modified to take into account the addition of the test cell insert. Detailed descriptions of the models used in the code are contained in Refs. 2 and 5.

\section{FPD-II+T COMPARED WITH FPD-II}

One of the goals of this paper is to present the ramifications of inserting a test-cell into an existing FPD-II device. This gection will give a comparison of parameters for an optimized FPD-II+T long test-cell configuration yielding $4 \mathrm{MW} / \mathrm{m}^{2}$ neutron wall loading with FPD-II parameters.

The introduction of the test cell into FPD-II makes the configuration more suaceptible to MHD instabilities and, thus, puts severe constrainta on the particle pressures sustainable in the test cell and central cell of FPD-II+T. (In the context of FPD-II+T modeling, "central cell" refers to the region outside of the test cell.) This is because the simple mirror geometry of the test cell gives rise to more bad curvature drive than the central cell section it replaces.

Assuming a peak plug beta of 0.45 , teat cell and central cell beta limits for stability of the flute interchange mode and the (dominant) $m=1$ ballooning mode ${ }^{6}$ were genurated using the TEBASC07 MHD code. The regults showed that not only were the central cell beta limits more restrictive than in FPD-II but an increase in the peak test cell beta, $\beta_{t c}$, nust be balanced by a corresponding decrease in the peak central cell bet $8, B_{c c}$. For example, $B_{t c}=0.53$ required $B_{C C}=0.36$ compared with 0.90 in FPD-II. Also, as the ratio of test cell length to central cell length increases, the allowed beta values for stability increase. Finally raising bet in the MHD anchor region tends to ease central cell and test cell beta restrictions oomewhat. Hence, higher peak anchor betas ( 0.60 for the short test-cel1, 0.40 for the long case compared with 0.21 in FPD-II) are a feature of the designs presented in this paper.

The DT ions in the central ceil are categorized in terms of three separate but inter- acting populations, HOT ions in the test cell and HOT* and COLD ions in the central cell (see Ref. 5). HOT ion behavior is described using a Logan-Rensink plug mode $1 .{ }^{8}$ This model includes losses due to pitch-angle scattering of hot ions with other hot ions and losses due to drag on electrons. In FPD-II+T, HOT ions lost from the test cell become part of the COLD or HOT* populations. This partially filled loss cone tends to increase the confinement of HОт ions. Multi-region Fokker-Planck calculations were used to calculate a calibration factor which was used in the code models to account for the increased confinement.

The HOT ion confinement times are significantly shorter than those for COLD ions. This is because the HOT ions are only mirror confined in the test cell while the COLD ions are both mirror confined in the central cell and electrostatically confined by the potential peak in the plug region, $\phi_{c}$. As a result, large currents of mixed DT neutral beams (571 A) are required to replace the HOT ions that pitch-angle scatter out of the test cell mirror.

COLD particles are removed from the device via fusion reactions, neoclassical transport, radial (transition drift pump) losses, and axial (Pastukhov) losses. In FPD-II+T the first two mechanisms are generally small and the radial losses are constrained by the drift pump capabilities, so the large convective current due to HOT ions which pitch angle scatter from the test cell and HOT* ions which slow down in energy mat be balanced by axial losses which are significantly larger than those for FPD-II. This is accomplished by lowering $\phi_{c}$ from $190 \mathrm{kV}$ to $61 \mathrm{kV}$. This, in turn, leads to a decrease in the Pastukhov confinement parameter, (nt) axial, c, from $1.0 \times 10^{16}$ to $2.5 \times 10^{14} \mathrm{~s} / \mathrm{cm}^{3}$. In contrast, FPD-II has no neutral beam injection in the central cell, so the three 108 mechaniana above mut be balanced by significant cold fueling current using a pellet injector system. No pellet injection is required in current FPD-II+T designs. Finally, for this case the transition trapping current is down to $107 \mathrm{~A}$ from $165 \mathrm{~A}$ in FPD-II.

Operation of FPD-II with a test cell requires higher anchor beta for MHD stability. This in turn requires that the anchor ion cyclotron resonance heating (ICRH) power increase significantly, from $0.26 \mathrm{MW}$ in FPD-II to $0.88 \mathrm{Mw}$. In addition, the injection energy of the sloshing ion neutral beams in FPD - II+T is significantiy lower than in FPD-II $(280 \mathrm{keV}$ compared with $475 \mathrm{keV}$ ) consistent with maintaining the effective mirror ratio for sloshing ions greater than one (to confine the sloshing ions) and maintaining the peak to midplane loshing density ratio greater than two (to ensure plug microstability). The sloshing ion beam power is reduced significantly (from $1.37 \mathrm{MW}$ to $0.14 \mathrm{MW}$ ) a well. Finally, since FPD-II+T configurations have smalls pasaing densities than FPD-II, 
aignificantly lower ECRH power at the potential peak ( $0.12 \mathrm{MW}$ compared with $0.35 \mathrm{MW})$ is

required. The ECRH requirements at the barrier location are not significantly different frow those in FPD-II. In this case the reductions in scattering and drag power losses due to lover density are balanced by an increase in synchrotron radiation losses (from 6.36 kW to $9.84 \mathrm{MW}$ ) due to increased hot electron energy.

\section{TEST CELL PARAMETRIC STUDIES}

To reduce the cost of the upgrade, FPD-II baseline parameters formed the basis for the FPD-II+I design. Certain aspects of the FPD-II design, such as machine dimensions and coil arranyement, were considered fixed for $F P D-I I+T$. On the other hand, some FPD-II+T systems requirsments ( $E$ CRH powers, sloshing ion neutral beam powers, and drift pump currents) were constrained to have values near, or below, the FPD-II baseline to permit use of existing FPD-II reactor systems in the upgrade. Finally the FPD-II+T mode of operation results in significantly higher ICRH power requirements and direct converter heat loads than in FPD-II. These parameters are ultimately limited by engineering considerations.

The FPD-II+T design is also subject to a number of physics constraints. First, MHD stability against the $m=1$ ballooning mode requires that betas in the test cell and central cell be limited to the stability regions calculated from MHD theory. Second, confinement of the sloshing ions in the plug region further requires that the effective mirror ratio for sloshing ions be greater than one. Third, for microstability of the sloshing ions, the peak to midplane sloshing ion density ratio must also be greater than two. Fourth, two atream instabilities in the transition region may result if $8_{D T}$ (the ratio of the total cold DT ion density (pessing + trapped) to the cold passing density] is less than two. Finally, the Futch-LoDestro formula ${ }^{9}$ for the trapping current of DT ions may be inaccurate for $\mathrm{BDT}<2.0$. In this study $\mathrm{BDT}$ is taken to be 2.3 which satisfies these constraints and also minimizes the trapping current.

The sensitivity of test cell neutral beam injector performance to the variation of the beam injection angle has been examined. Resulta have been generated for a short test cell configuration with $B_{c c}=0.20, B_{r c}=0.35$, (nt $)_{\text {axial, } c}=1.0 \times 10^{15} \mathrm{~s} / \mathrm{cm}^{3}$. In addition, densities and temperatures throughout the machine were allowed to vary. As the injection becomes more nearly perpendicular, the neutral beam current and power required to produce a neutron wall loading of $3 \mathrm{~mW} / \mathrm{m}^{2}$ decrease. In the Logan-Rensink model incressing the injection angle results in an increase in the mirror confinement of the hot ions. Since the test cell beta and the test cell wall loading are held constant, the hot DT ion denaity and energy also remains approximately constant. The increased confinement results in lower required injection currents to hold the hot density constant. As the injection current decreases, power balance in the test cell requires the injection energy to increase. This also results in better coninement of the hot ions. The confinement improves sufficiently with increasing injection angle and injection energy for the decrease in neutral beam current to be more rapid than the increase in neutral beam energy. Thus, the neutral beam power drops with injection angle. Long teat cell configurations show the same qualitative behavior.

This parametric also showed that the most economical test cell performance (in terms of neutral beam power) is available for perpendicular injection. This is, however, undesirable on the basis of other considerations. Perpendicular injection results in an axial density profile severely peaked near the test cell midplane. This reduces the neutron wall loading at the edges of the blanket test modules to values much lower than those quoted here. In addition, it makes the test cell hot ion distribution susceptible to Alfven ion cyclotron (AIC) instabilities. For the parametrics to follow, injection at $80^{\circ}$ is used for both the short and long test cell cases.

The effects of the variation of ( $\pi$ ) axial, on test cell neutral beam performance have been studied. The results give an example of th. close connection between test cell behavior and that of the rest of the machine. It was found that reducing the confinement of the COLD ions leads to a fairly large increase in the required test cell neutral beam current coupled with $a$ lower neutral beam injection energy. These results are explained as follows. With lower axial confinement, the axial power loss for CoLD DT ions is increased. Energy conservation requires that this 108 be balsnced by an increase in the power entering the COLD population. This is accomplished by an increase in energy convection from the HOT ion population in the test cell to the COLD population in the central cell. Since the HOT density and energy remain constant as $(\pi \pi)$ axial is varied, this increased convection is made possible by a decrease in the injection energy which lowers the confinement of the HOT ions. The injection current increases proportionally to hold the HOT density constant. Also, each Cold particle loot axially, on average, carries away more energy than does a HOT particle pitch-angle scattering out of the test cell. Thus, the HOT-COLD particle flux must be larger than the axial cold ion loss for energy balance. This also explains the decrease in the required COLD fueling current with decreasing (nt) $a x i a l, c$.

Finally the resulrs showed that a subatantial reduction in the transition region trapping current can be achieved by reducing the axial 
confinement of COLD ions. This is because the particle throughput is then primarily removed axially racher than radially. This results in a modest increase in the heat flux impinging on the direct converter. Since the decrease in trapping current, with the accompanying decrease in drift pump requirements, is obtained with virtually no increase in test cell neutral beam power, it is desirable for FPD-II+T configurations to operate at the lowest ( $n \tau$ ) possible. This minimum axial confinement is clearly the value that results in zero required COLD fueling current. Long test cell configurations show the same behavior and are, therefore, operated in a similar mode.

ihe sensitivity of test-cell performance to neutral beam injector parameters has been examined. As expected, the results showed that increased wall loading is accomplished by raising the neutral beam current and power. This can be explained as follows. At constant $B_{t c}$, wall loading is increased by raising the HOT ion density and correspondingly lowering the HOT ion energy. This is possible because the fusion reaction rate parameter for the HOT ions varies slowly in the energy regime considered here. 10 A lower average HOT ion energy requires a lower injection energy for energy balance. This, in turn, results in reduced HOT ion confinement and, therefore, increased neutral beam current and power requirement $s$. Decreasing $\beta_{t c}$ at constant wall loading has a similar effect. To maintain a given wall loading at lower test cell beta the HOT ion average energy must again decrease so that the HOT ion density (and, thus, the test cell fusion power) remains approximately constant.

It was also found that plasma parameters are sensitive to changes in the COLD ion temperature, $T_{i} c$. Central cell energy balance (at constant $\beta_{t c}$ ) requires that when the HOT ion energy is decreased (to increase wall loading) the cold ion cemperature must decrease. Hence, the Futch-Lodestro trapping formula predicts that the trapping current should riae with increasing wall loading ( $\beta_{t c}$ held constant) or decreasing $B_{t c}\left(\Gamma_{\text {tc }}\right.$ held constant). Another operating parameter directly sensitive to changes in $T_{i}, c$ is the anchor ICRH power. Devoto has shown in Ref. 6 that the anchor hot ion energy is limited by the conatraint that the anchor ion drift frequency be smaller than the growth rate for MHD instabilities in the central cell. As a result of this condition, the anchor hot ion energy is proportional to the COLD ion temperature. Therefore, at constant anchor beta, decreasea in $T_{i} c$ result in increases in anchor ion density and increases in ICRH power requirements.

Pinally, the power requirements of the ECRH and loshing ion neutral beam systems are indirectly affected by the variations in wall locing and/or teat cell beta through the ion temperature $I_{i, c}$. At constant central cell beta, decreases in $T_{i}, c$ result in a larger COLD in density. This, in turn, causes larger COLD passing ion densities to be mapped into the end cells (see Ref. 4). The sloshing ion neutral beam power and the ECRH power at the potential peak increase with increasing passing density. Also, at constant plug beta, increases in passing densities lead to decreases in the hot electron energy (see the discussion in Sec. 2). With lower hot electron energy, synchrotron power losses are reduced along with the ECRH requirements at the barrier point.

\section{ATTRACTIVE TEST CELL CONFIGURATIONS}

The results from the previous section can be used to develop optimized parameter sets for the short and long FPD-TI+T configurations. This section will describe a number of tiese paramecer sets, any of which could form the physics basis for an engineering design of FPD-II+T. Derails are given in Ref. 11. Operating parameters for short test cell configurations with $3.0 \mathrm{MW} / \mathrm{m}^{2}$ and $3.5 \mathrm{~mW} / \mathrm{m}^{2}$ neutron wall loading. respectively, have been obtained. Long test cell configurations producing $3.0 \mathrm{~mW} / \mathrm{m}^{2}, 4.0$ $\mathrm{MW} / \mathrm{m}^{2}$, and $6.0 \mathrm{MW} / \mathrm{m}^{2}$ have also been found.

These test cell configurationa were optimized primarily with respect to test cell neutral beam power by varying the test cell and central cell betas. This was based on the assumption that the test cell neutral beam injector would account for much of the increase in the capital and operating costs of FPD-II+T over FPD-II. For short test cell configurations, MHD beta 1 imits are so severe that operation on the marginal stability line is required to achieve acceptable wall loadings ( $\Gamma_{t c} \geq$ $\left.3.0 \mathrm{MW} / \mathrm{m}^{2}\right)$. In these cases, no real optimization of test cell neutral beam power is possible since each point along the stability line yields a unique wall loading (which increases with $\left.B_{t c}\right)$. In contrast, long test cell cases are not as limited by MFC stability so a number of combinations of test cell and central cell beta result in sufficiently high wall loading. As the previous section suggests, the test cell beta can be increased to minimize the neutral beam power required to obtain a given wall loading. This results in an increase in the injection energy. However, due to considerations of the beam neutralization efficiency (which drops significantly with increasing energy), this injection energy has been limited to $100 \mathrm{keV}$ in this study. This constraint sets the central cell beta value.

A comparison between optimized short and long test cell configurations yielding $3.0 \mathrm{MW} / \mathrm{m}^{2}$ test-cell walls loading is given in Table 1 . since the two configurations producs the same wall loading, it is not surprising that their HOT ion densities are similar $\langle\langle\sigma\rangle\rangle_{\text {hot }}$ varies slowly with the HOT ion energy in the range considered). The lower test cell beta associated with the short configuration, however, $B$ ives a 
Table 1. FPD-II+T parameters for short and long test cell configurations.

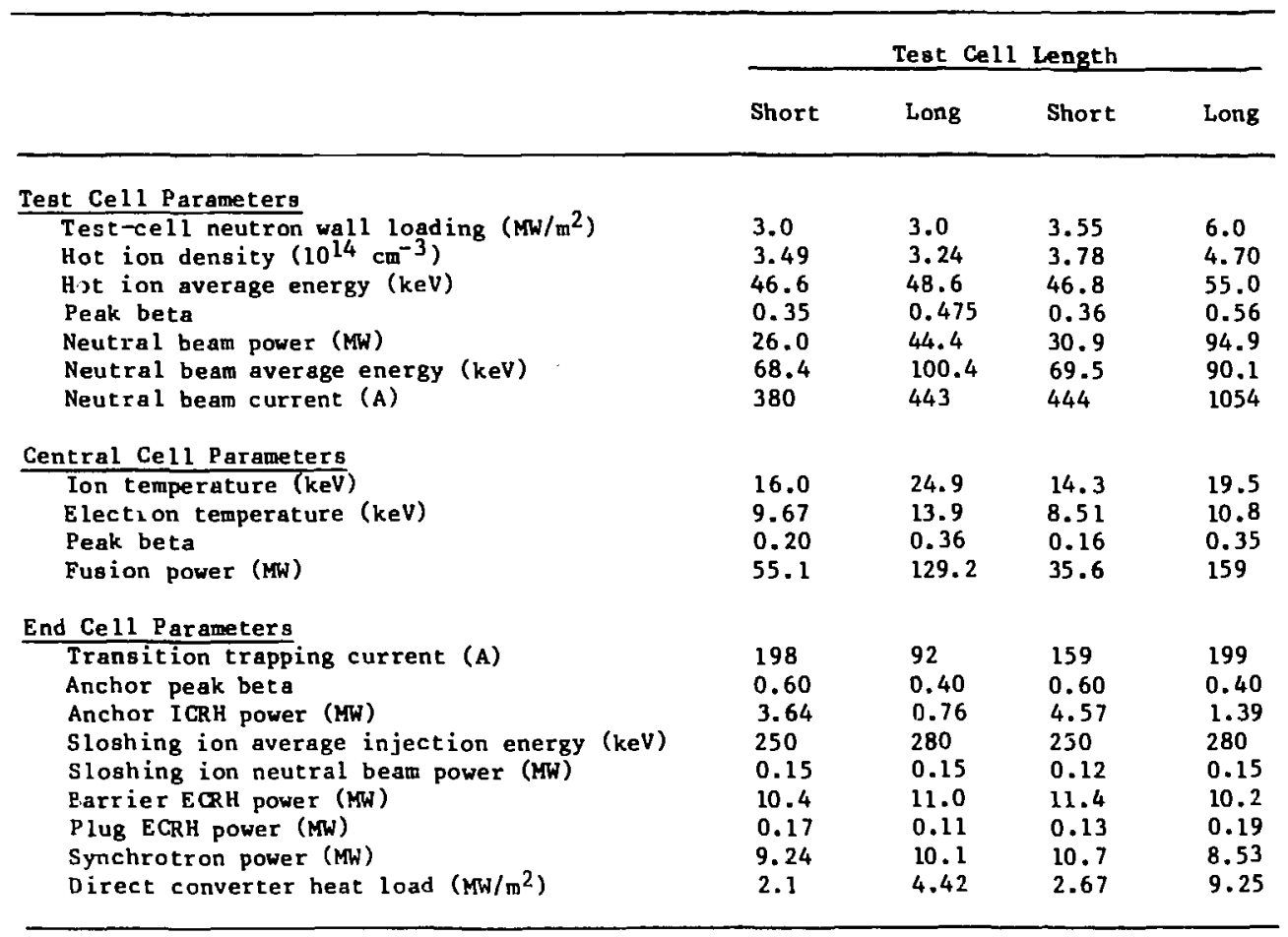

lower HOT ion energy and, thus, a significantly lower neutral beam injection energy. The resulting decrease in HOT ion confinement, in turn, leads to neutral beam powers and currents not much different from those required for the long test cell (despite the fact that the short test cell has a much smaller effective volume). Consistent with the lower HOT energy and central cell beta, the COLD ion temperature for the short test cell case is only $16 \mathrm{keV}$ compared to $24.9 \mathrm{keV}$ for the long test cell. This lower COLD ion temperature directly leads to larger qlues for the trapping current and anchor ICRH power (the anchor beta used affects this as wel1). The COLD ions in the long test cell version of $F P D-I I+T$, however, are not as well confined as those for the short test cell version $\left(\phi_{c} / T_{i}, c\right.$ for the long test cell configuration is smaller--see Ref. 4). This results in larger direct converter heat loads. Finally, in both cases, no COLD fueling is required.

FPD-II+T configurations with short test cells possess a fundamental limit on the test cell vall loading they can achieve (given the constraints of this study). This limit results because the anchor ICRH requirements associated with wall loadings above this value cannot be met due to access limitations. In FPD-II, each of four antenna-type ICRH launchers in the two end cells (eight launchers total) can supply approximately $1 \mathrm{MW}$ of power at about $30 \%$ efficiency. This system could not meet the requirements of any short tesi cell configuration. However, waveguide-type launchers, which can provide up to 2 MW of power each, at similar efficiencies, can be substituted to provide a maximum of $4.5 \mathrm{MW}$ of ICRH power. This allows a maximum neutron wall loading of $3.55 \mathrm{~mW} / \mathrm{m}^{2}$ to be obtainable in the short test-cell configuration. Parameters for this case are given in Table 1 .

The wall loading limit for short test cell configurations is a direct result of the low temperature and high anchor beta operation demanded by MHD beta limits. Long test cell configurations are not as severely constrained and, hence, would be expected to have a much higher wall loading limit. Long test cell configurations producing wall loadinge of $4.0 \mathrm{~mW} / \mathrm{m}^{2}$ and $6.0 \mathrm{MW} / \mathrm{m}^{2}$ with fairly smell anchor ICRH power requirements have been found. The $6.0 \mathrm{MW} / \mathrm{m}^{2}$ case is given in Table 1 . The results show that before the limit on ICRH power is exceeded, improvements in long test cell performance may become too costly due to 
rapidly growing test cell neutral beam current and power requirements.

\section{SUMMARY AND CONCLUSIONS}

The issues that must be considered when upgrading FPD-II to perform integrated nuclear testing using a test-cell insert have been presented. Test cells with $5.4 \mathrm{~m}$ and 12.8 mirror-to-nirror lengths were considered. The neutral-beam-driven test-cell can achieve reactor level neutron wall loading in the range from 3.0 to $6.0 \mathrm{MW} / \mathrm{m}^{2}$.

To minimize the cost of the upgrade, FPD-II+T utilizes the same coil arrangement and machine dimensions outside of the test cell region as FPD-II. For this same reason, most of the FPD-II+T end cell systems were held near or below the corresponding FPD-II baseline values. Anchor ICRH power requirementé and direct converter heat flux are significanty higher in FPD-I $\mathrm{I}+\mathrm{T}$.

A series of parametric studies were performed to optimize test cell performance. These parametrics showed that test cell neutral beam power requirements were reduced as injection angle and energy were increased. In addition, low axial confinement parameters were desirable since this reduced both drift pump and COLD fueling requirements. Finally, many crucial plasma parameters vere found to depend sensitively on the test cell beta. In particular, test cell neutral beam power and current requirements could be reduced by increasing the test cell beta up to the MHD stability limit. Performance in the short teat cell configurations was limited to wall loadings less than $3.5 \mathrm{~mW} / \mathrm{m}^{2}$ while long test cell configurations were 1 eso limited by MHD stability so wall loadings as high as $6.0 \mathrm{~mW} / \mathrm{m}^{2}$ were obtainable.

If wall loading less than $3.5 \mathrm{MW} / \mathrm{m}^{2}$ is acceptable, FPD-II+T with a ohort test cell will offer a fairly inexpensive way to provide blanket testing in a fusion environment. In this study, the only way to achieve higher wall loading is to make use of the more expensive long teat cell version of FPD-II+T. More wall loading could be achieved with a short test cell if the stringent MHD beta limits for these configurations could be raised. In this atudy, only one test cell magnetic field profile was considered. Careful field ghaping could yield a profile with more attractive MHD behavior. Even if this process yielded only slightly higher beta limits, large improvements in test cell performance would occur. Finally, one could conclude that FPD-II, due to its long central cell length (which makes it more susceptible to the $m=$ I ballooning mode), is not the ideal target machine for a test cell insert. Instesd, the FPD-III design with compact octopole and cells which features a much shorter central cell than FPD-II, might achieve much better test-cell performance.

\section{REFERENCES}

1. K. I. THOMASSEN and J. N. DOGGETT, Eds., Options to Upgrade the Mirror Fusion Test Facility, Lawrence Livermore National Laboratory, Livermore, CA, UCID-19743 (April 1983).

2. M. E. FENSTERMACHER and R. B. CAMPBELLL, Modeling and Optimization of MFTF- $\alpha+T$ High- $\Gamma$ Mode Performance, Lawrence Livermore National Laboratory, Livermore, CA, UCID-20284 (December 1984).

3. J. D. DOGGETT et al., FPD Interim Report, Lawrence Livermore National Laboratory, Livermore, CA, UCID-19975-1 (1984).

4. R. B. CAMPBEll, TMRBAR - A Code to Calculate Plasma Parameters for Tandem Mirror Reactors Operating in the MARS Mode, Lawtence Livermore National Laboratory, Livermore, CA, UETD-10675 (August 1933).

5. M. E. FENSTERMACHER and R. B. CAMPBELL, Physics Modeling of Tandem Mirror Devices with Test-Cell Inserts, Lawrence Livermore National Laboratory report in preparation.

6. B. G. LOGAN, C. D. HENN ING, G, A. CARLSON, R. W. WERNER et al., Mirror Advanced Reactor Study - Final Report, Laurence Livermore National Laboratory, Livermore, CA, UCRL-53480 (July 1984).

7. L. L. PEARLSTEIN et al., TEBASCO User's Guide, Livermore National Laboratory, Livermore, CA, UCID-19869 (Sept. 1983).

8. G. A. CARLSON et al., Tandem Mirror Reactcr with Thermal Barriers, Lawrence Livermore National Laboratory, Livermore, CA, UCRL-52B36 (September 1979); and B. G. Logan, A. A. Mirin, and M. E. Rensink, "An Analytic Model for Classical Confinement in Tandem Mirror Plugs," Nuc. Fus. 20, 1613 (1980).

9. A. H. FUTCH and L. L. LODESTRO, Collisional Trapping Rates for Ions in a Magnetic and Potential We11, Lawrence Livermore National Laboratory, Livermore, CA, UCRL-87299 (February 1982).

10. K. D. MARX et al., "Calculation of $\langle\sigma v\rangle_{D T}$ for Anisotropic Mirror and Toroidal Distributions," Nuclear Fusion 16, 702 (1976).

11. S. W. HANEY and M. E. FENSTERKACHER, "Test-Cell Modeling and Optimization for FPD-II, "Lawrence Livermore National Laboratory report in prepartion. 